education for primary care -short reports section

\title{
A fellowship in interim care - The GP extensivist experience
}

Dr Cheryl O'Connell GP Extensivist clinical fellow, MRCGP, BM, BA, MA, Dr Adam Fraser, Prof Michael Vassallo

Royal Bournemouth Hospital/Wessex GP education centre, England

Correspondence details: Christchurch Day Hospital, Fairmile Road, Christchurch, Dorset. Cheryl.o'connell@nhs.net

Keywords: Fellowship, Integrated care, geriatrics, multidisciplinary care, ST4 


\section{A fellowship in interim care - The GP extensivist experience}

Dr Cheryl O’Connell, Dr Adam Fraser, Prof Michael Vassallo

\section{Context}

In January 2015 I had recently completed my CCT and become a fully-fledged GP. I was excited by the opportunities available to me now that I had completed the training programme, and was looking do something a little different. I have always been interested in geriatrics, but I also love seeing patients in their own homes as a GP. A fellowship as a GP Extensivist supervised by Adam Fraser at Bournemouth University and Michael Vassallo at Royal Bournemouth Hospital gave me the opportunity to do both. The post was part-time, so I was able to work in a GP practice to maintain my skills and stay fully grounded in my GP roots.

\section{Project aim /research question(s)}

The Extensivist one-year posts were designed to give newly qualified GPs an opportunity to gain additional skills in managing elderly, complex and vulnerable patients. I was given an open ended remit; simply to work with the Extensivist model developed in California in mind (see text box 1) and to explore how to apply it to the population served by Royal Bournemouth Hospital. There was dedicated CPD time to allow me to develop my geriatric skills and take the Diploma in Geriatric Medicine and I was given the opportunity to try several different approaches to develop the model. It was exciting to be involved in a project that was so forward thinking and open to new ideas.

\section{Description}

I worked in the Christchurch area, where $30 \%$ of the population is aged over 65 [2] ; working in this small area allowed me to build close relationships with GPs and community teams, which was essential for the role. I tried several different ways of sourcing appropriate referrals and explored what Extensivists were doing elsewhere in the UK. A common theme seemed to be working within a multidisciplinary team and with this in mind I became involved in the development of a multidisciplinary community hub. I worked closely with nurses, physiotherapists, occupational therapists, care and rehab assistants and social workers to deliver a comprehensive geriatric assessment at home for patients with complexity. With daily virtual ward rounds and weekly multidisciplinary team meetings there is regular feedback on patient's progress. I found that in working this way I was able to select the most appropriate patients and effectively manage a number of complex patients under my care.

\section{Outcomes}


In seven months working with the Christchurch hub, I have been overseen the care of 181 patients recently discharged from hospital, and estimate having prevented up to 20 readmissions by providing joined-up-care. Informal feedback from patients, GPs and the hospital has been positive (see text box 2).

In terms of my personal development, over the year I learned a great deal about geriatric conditions, managing complexity and most significantly juggling risk, whilst having the comfort blanket of a supported learning environment. Having recently been a trainee, I now found myself in the role of the most senior clinician in the team, leading meetings and being looked to for management advice. I have developed new skills in leadership and am now am finding it easier to manage a workload as part of a close team.

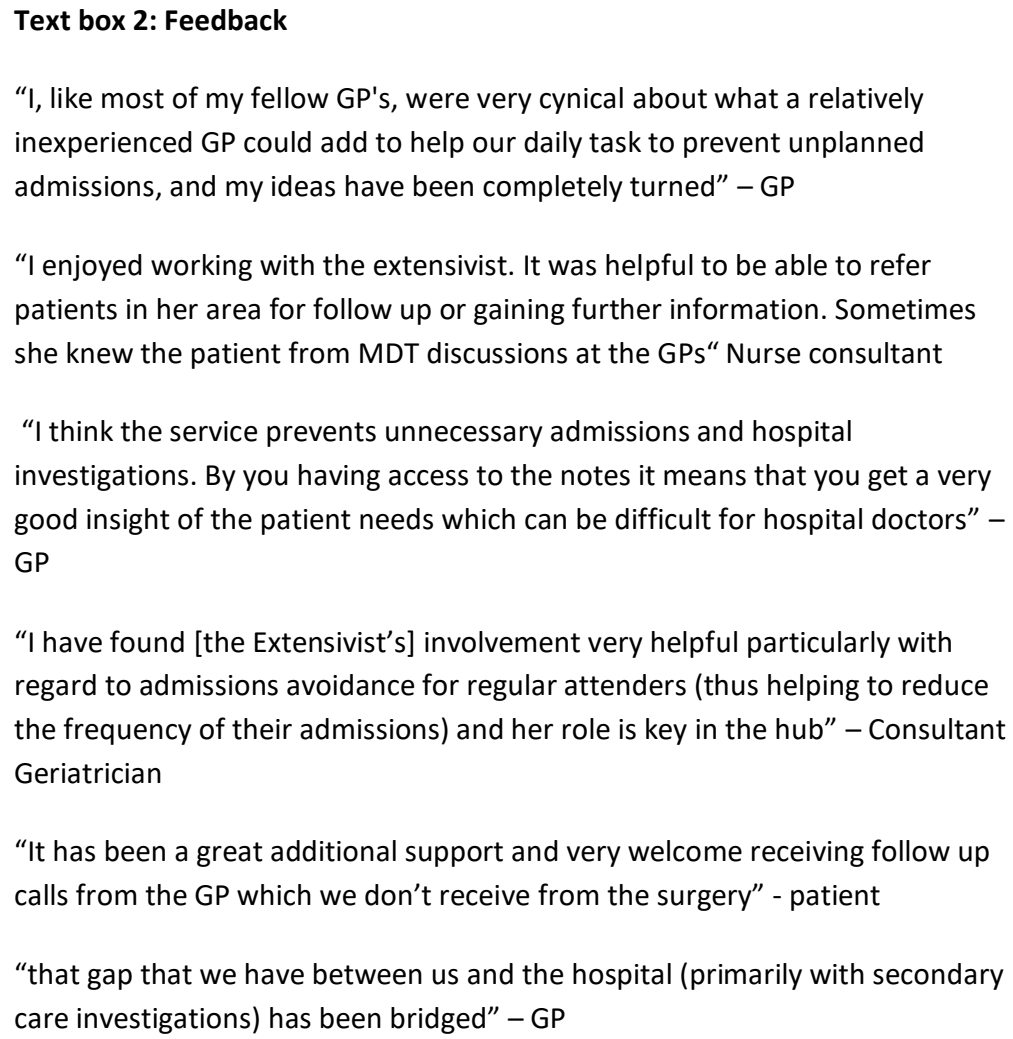

\section{Conclusions}

I feel privileged to have had this opportunity and have really enjoyed working as an extensivist, with many 'patient success stories'. It is satisfying to have the time and resources to be able to proactively manage a patient in the comfort of their home, to work closely with the GPs who know the patients well, to have a team of colleagues I can call on for advice and to feed back their progress. With a flexible daily schedule, I am able to visit a patient for as long as is required, and have the time to work alongside patients and families and to make plans for their future care, with huge massive positive impacts on their quality of life. This is hugely rewarding and something I have been less able to do with the growing pressures of everyday general practice.

This post has given me the opportunity to break into a new and exciting area of general practice, which is rapidly developing. There are already around a dozen GP Extensivists in the UK, and the concept is gathering momentum [3]. On the basis of the work I was doing with the hub, Dorset healthcare created a permanent position for the role I had developed, and they are planning to set up more hubs. The role fits well with the NHS 5 year forward view for integrated community care [4] and there is already a lot of buzz about blurring the boundaries between primary and secondary care. I'm confident that there will soon be many more extensivists cropping up!

\section{References}

[1] Lessons from CareMore: A Stepping stone to Stronger Primary Care of Frail Elderly Patients. The American Journal of Accountable Care [cited $7^{\text {th }}$ August 2017] Available from: 
http://www.caremore.com/ /media/Files/News/20150615\%20AJMC\%20\%20Lessons\%20From\%20CareMore.ashx

[2] Area profile for Christchurch [Internet] Dorset County Council. Dorset Statistics. [cited $7^{\text {th }}$ August 2017] Available from: https://apps.geowessex.com/stats/AreaProfiles/District/christchurch

[3] Extensivist Model of Care [internet] Health Services Management Centre Library [cited $7^{\text {th }}$ August 2017] Available from: http://www.birmingham.ac.uk/Documents/college-social-sciences/socialpolicy/hsmc-library/snappy-searches/Extensivist-model-of-care.pdf

[4] NHS Five Year Forward view. NHS England. Published October 2014. [cited $7^{\text {th }}$ August 2017] Available from: https://www.england.nhs.uk/wp-content/uploads/2014/10/5yfv-web.pdf 